\title{
Os NAPNEs e o Plano Educacional Individualizado nos Institutos Federais de Educação
}

\author{
NAPNEs and Individualized Educational Plan at Federal Institutes of \\ Education
}

\begin{abstract}
NAPNE y planificación educativa individualizada en los Institutos Federales de Educación
\end{abstract}

\author{
Andréa Poletto Sonza \\ Professora doutora no Instituto Federal de Educação, Ciência e Tecnologia do Rio Grande do Sul, Bento \\ Gonçalves, Rio Grande do Sul, Brasil. \\ andrea.sonza@ifrs.edu.br
}

ORCID - http://orcid.org/0000-0003-0033-4409

Carla Ariela Rios Vilaronga

Professora doutora na Universidade Federal de São Carlos, São Carlos, São Paulo, Brasil. carlavilaronga@gmail.com

ORCID - http://orcid.org/0000-0001-6050-2369

\section{Enicéia Gonçalves Mendes}

Professora doutora na Universidade Federal de São Carlos, São Carlos, São Paulo, Brasil. eniceia.mendes@gmail.com

ORCID - https://orcid.org/0000-0003-3673-0681

Recebido em 11 de agosto 2020

Aprovado em 14 de agosto de 2020

Publicado em 17 de novembro de 2020

\section{RESUMO}

Conforme cresce o ingresso de estudantes Público-Alvo da Educação Especial (PAEE) em instituições educacionais comuns aumenta a demanda por ações que proporcionem participação e aprendizagem desses estudantes. No contexto da Rede Federal de Educação Profissional e Tecnológica há Núcleos de Atendimento/Apoio às Pessoas com Necessidades Educacionais Específicas (NAPNEs) e o objetivo desse artigo consistiu em analisar o papel dos núcleos em dois Institutos Federais de Educação Brasileiros, bem como refletir sobre a importância do Plano Educacional Individualizado (PEI). O estudo, de caráter documental, envolveu a análise das orientações para as ações dos NAPNEs e como é proposto o desenvolvimento do PEI. Evidenciou-se que os NAPNEs, apesar de envidarem esforços para assumir parte considerável do papel de ensino, pesquisa e extensão, têm apresentado diversas fragilidades. A ampliação do objetivo do Núcleo para ações que propõem medidas individuais demanda uma rede multiprofissional capacitada. O PEI, por sua vez, responde a uma necessidade de construção colaborativa da instituição, visando traçar objetivos e orientações focalizados na acessibilidade curricular para esses estudantes. O maior obstáculo, entretanto, tem sido a insuficiência de profissionais capacitados e uma demanda latente identificada é a contratação de professores de educação especial. Nesse contexto, os NAPNEs, embora assumam um papel relevante nos Institutos estudados, da forma como são constituídos não são suficientes para efetivar o 
http://dx.doi.org/10.5902/1984686X52842

direito dos discentes PAEE, sendo necessário lutar pela implantação de políticas públicas para remoção das barreiras no processo de escolarização nessas instituições.

Palavras-chave: Educação profissional e tecnológica; Acessibilidade; Plano educacional individualizado.

\section{ABSTRACT}

As more students with educational special needs enters common educational institutions, the demand for actions that provide participation and learning for these students increases. In the context of the Federal Network of Professional and Technological Education there are Support Service for People with Specific Educational Needs (SSPSEN) and the objective of this article was to analyze the role of the centers in two Brazilian Federal Institutes of Education, as well as reflect on the importance of the Individualized Educational Plan (IEP). The study involved to analyze the guidelines for the actions of SSPSEN in the two institutes, and how is proposed the IEP development. It became evident that SSPSEN, despite making efforts to assume a considerable part of the teaching, research and extension role, have presented several weaknesses. The expansion of the centers' objective to propose individual measures requires a trained multiprofessional network. The PEI, in turn, responds to the need for collective and collaborative construction of the institution to outline objectives and guidelines focused on curricular accessibility for these students. The biggest obstacle, however, has been the lack of trained professionals and an identified latent demand is the hiring of special education teachers. In this context, SSPSEN although assuming a relevant role in the Institutes studied, as they are currently constituted are not sufficient to enforce the right of PAEE students, being necessary to fight for the implementation of public policies to remove barriers in the schooling process in these institutions.

Keywords: Professional and technological education; Accessibility; Individualized educational plan.

\section{RESUMEN}

A medida que el público objetivo de los estudiantes de Educación Especial (PAEE) ingresa a instituciones educativas comunes, aumenta la demanda de acciones que brinden participación y aprendizaje a estos estudiantes. Na Red Federal de Educación Profesional y Tecnológica, existen Centros de Servicio/Apoyo para Personas con Necesidades Educativas Específicas (CAPNEE) y el objetivo de este artículo fue analizar el papel de los centros en dos Institutos Federales de Educación de Brasil, así como reflexionar sobre importancia del Plan Educativo Individualizado (PEI). El estudio documental involucró el análisis de las pautas para las acciones de CAPNEE, y cómo se propone el desarrollo del PEI. Se hizo evidente que las CAPNEE, a pesar de hacer esfuerzos para asumir una parte considerable de la función de enseñanza, investigación y extensión, han presentado varias debilidades. La expansión del objetivo del Núcleo a las acciones que proponen medidas individuales, requiere una red multiprofessional capacitada. EI PEI, a su vez, responde a la necesidad de una construcción colaborativa de la institución para delinear objetivos y lineamientos enfocados en la accesibilidad curricular. Sin embargo, el mayor obstáculo é a falta de profesionales capacitados y una demanda latente identificada es la contratación de maestros de educación especial. En este contexto, los CAPNEE, aunque asumen un papel relevante en estos Institutos, ya que actualmente están constituidos, no son suficientes para hacer cumplir el derecho de los 
estudiantes PAEE, siendo necesarios para luchar por la implementación de políticas públicas para eliminar las barreras en el proceso escolar en estas instituciones.

Palabras clave: Educación profesional y tecnológica; Acessibilidade; Plan educativo individualizado.

\section{Introdução}

Os NAPNEs (Núcleos de Atendimento/Apoio às Pessoas com Necessidades Específicas) são proposições da Secretaria de Educação Profissional e Tecnológica do Ministério da Educação (SETEC/MEC), por meio do Programa TECNEP (Tecnologia, Educação e Profissionalização para Pessoas com Necessidades Educacionais Específicas).

O objetivo da iniciativa foi ampliar estratégias para consolidar uma política de educação inclusiva ${ }^{1}$ nas Instituições Federais de Ensino da educação básica, ensino técnico e tecnológico, atuando diretamente no contexto escolar, disseminando conceitos, divulgando experiências e sensibilizando as comunidades escolares para a questão das necessidades específicas. Atualmente, a Rede Federal de Educação Profissional, Científica e Tecnológica (RFECPT) ${ }^{2}$ conta com NAPNEs em diversas instituições, ultrapassando o número de 600 núcleos em funcionamento (NASCIMENTO; PORTES, 2016).

Assim, os NAPNEs têm para a Rede Federal de Educação Profissional e Tecnológica, a mesma importância que as Salas de Recurso Multifuncionais exerce nas redes municipais e estaduais de ensino ou o Projeto INCLUIR, nas Universidades Federais. Isso demonstra a relevância da criação e da atuação dos núcleos nessas instituições, que atuam como espaços de reflexão, luta e concretização de ações em prol da inclusão plena, permanência e êxito dos estudantes com necessidades educacionais específicas.

Neste cenário, trazemos, dentre as pautas de discussão, reflexões acerca das conquistas e desafios para a implantação da política nacional para educação inclusiva no contexto da Rede Federal de Educação Profissional, Científica e Tecnológica (EPCT).

Em relação ao público atendido, ao apresentar o conceito de estudantes com "necessidades educacionais específicas", nomenclatura adotada em algumas das instituições que compõem a Rede Federal de EPCT, propõe-se a ampliação do público para além dos discentes com alguma deficiência, transtorno do espectro autista e altas habilidades/superdotação. Estudantes com transtornos funcionais específicos ${ }^{3}$ ou com severas limitações no aprendizado, em decorrência de perda de memória ou outras 
http://dx.doi.org/10.5902/1984686X52842

condições causadas por AVC, acidentes diversos, dentre outros, também são comumente assistidos pelas instituições.

É importante ressaltar que na maioria das instituições que compõem a Rede de Educação Profissional e Tecnológica não existe a presença do professor de Educação Especial e da Sala de Recursos Multifuncional. Algumas instituições, por meio do antigo Projeto Incluir, ou de recursos destinados à inclusão vindos da Secretaria de Educação Profissional e Tecnológica do Ministério da Educação, ou mesmo com recursos próprios, conseguiram adquirir alguns dispositivos, equipamentos ou recursos de Tecnologia Assistiva ${ }^{4}$, ou mesmo desenvolvê-los a baixo custo, mas essa não representa a realidade da maioria delas.

No que tange ao financiamento e ao Atendimento Educacional Especializado, previstos na Política de Educação Especial (BRASIL, 2008), infelizmente não ocorreu sua efetivação na Rede Federal de EPCT, que, ao contrário das Redes Estaduais e Municipais, não dispõe de códigos de vagas para a contratação desse profissional.

Por isso, defende-se aqui, que mesmo considerando a importância dos NAPNEs no contexto dos Institutos Federais, como espaços importantes que primam pelo ingresso, permanência e êxito dos estudantes com deficiência e/ou outras especificidades, que os mesmos não substituem o papel do educador especial no Ensino Médio, Técnico e Tecnológico. Ressalta-se que o Atendimento Educacional Especializado (AEE) deva ser garantido durante todo o período de escolarização desses estudantes, considerando-se o princípio de verticalização proposto pela política nacional, ao referir a "transversalidade da modalidade de Educação Especial desde a educação infantil até a educação superior" e a oferta do "atendimento educacional especializado" (BRASIL, 2008, p. 13).

A Lei Brasileira de Inclusão da Pessoa com Deficiência (BRASIL, 2015, p. 6) fala sobre o ensino em salas inclusivas, trazendo a necessidade da criação de um

III - projeto pedagógico que institucionalize o atendimento educacional especializado, assim como os demais serviços e adaptações razoáveis, para atender às características dos estudantes com deficiência e garantir o seu pleno acesso ao currículo em condições de igualdade, promovendo a conquista e o exercício de sua autonomia;

Entende-se que esses docentes com formação em Educação Especial são peças fundamentais, não somente para atuação na Sala de Recursos Multifuncionais, que inclusive não foram previstas na Rede Federal de EPCT e nem tiveram financiamento para aquisição de materiais, mas para o trabalho em parceria com o professor da sala comum, 
http://dx.doi.org/10.5902/1984686X52842

por meio da proposta de ensino colaborativo, na qual esses dois professores planejam, realizam e avaliam o ensino (VILARONGA; MENDES, 2014).

Neste cenário, destaca-se que o contexto das instituições que compõem a referida Rede na educação pública se dá, principalmente, pela verticalização do ensino na educação profissional e tecnológica, com propostas que englobam cursos técnicos de nível médio, graduação e pós-graduação.

O ingresso de estudantes é realizado por editais próprios de seleção ou pelo Exame Nacional do Ensino Médio (ENEM), nos quais, desde 2016, existe a previsão de reserva de vagas específicas para alunos com deficiência, por meio da Lei no 12.711/2012 (BRASIL, 2012). Tal reserva considera fatores como vulnerabilidade social, deficiência e outras características que historicamente foram agentes de exclusão. À Lei 12.711/2012 foi acrescida a inclusão das pessoas com deficiência ao público-alvo das cotas por meio do art. 5ำ da Lei $n^{\circ}$ 13.409/2016, fator que possibilitou a ampliação de matrículas de estudantes PAEE no contexto da Rede Federal de EPCT. Apesar disso, ainda não se pode mensurar esse aumento por meio de números, pois os dados estatísticos nacionais ainda não englobaram as instituições que compõem a referida Rede de forma discriminada em seus relatórios.

Entretanto, a garantia legal desse público não é somente de ingresso, pois está previsto, no artigo $1^{\circ}$ da Lei $n^{\circ} 13.146$, "assegurar e promover em condições de igualdade o exercício dos direitos e liberdades fundamentais das pessoas com deficiência, visando à inclusão social e a cidadania" (BRASIL, 2015, p. 1), entre eles, o espaço escolar.

A Rede Federal de EPCT, mesmo fazendo parte desta política de inclusão educacional, não possui a mesma estrutura física e humana, principalmente pela origem diferenciada de cada escola, no contexto de cada estado. Isso acarreta diferentes composições de equipes do NAPNE, como observado por Rodrigues Santos (2020), em sua pesquisa realizada com a previsão nos documentos oficiais dos NAPNEs de 36 Institutos Federais (IFs) do Brasil. A autora relata que, dos documentos analisados ${ }^{5}$ sobre os participantes do NAPNE em cada IF, encontrou a previsão de participação docente (26 documentos); pedagogo (24); técnico administrativo (24), psicólogos (22) discentes (21), assistente social (21), familiares (17). O que chama atenção é a previsão dos profissionais que deveriam atuar com o estudante PAEE, conforme a prerrogativa de apoio em número menor, como tradutor-intérprete de Libras (13), docente da educação especial (8), docente de Libras (3), transcritor de Braille (3), Revisor de Braille (3), Guia-intérprete (1). 
http://dx.doi.org/10.5902/1984686X52842

A constatação dessa equipe, entretanto, não significa que cada instituição em funcionamento no município, considerando a estrutura multicampi dos estados, possui, na efetividade, vários profissionais, ou que serão encontrados esses profissionais em cada campus do Instituto em que foi referenciado o documento de constituição dos NAPNEs. Alguns relatos são do funcionamento de núcleos com equipes restritas a uma única pessoa, que assume a função de presidir e de realizar as atividades idealizadas relacionadas ao ensino, pesquisa e extensão. Vale ressaltar que não foram previstas políticas de financiamento para os núcleos, nem função gratificada para a pessoa que assume a de coordenação do NAPNE.

Outro fator que merece destaque é a formação de uma grande parcela dos docentes atuantes no ensino técnico e tecnológico, que, por terem formação inicial e na pósgraduação na área técnica e nas engenharias, iniciam o processo de se tornar professores após a realização do concurso para o cargo; contexto no qual a parceria com o educador especial seria de extrema importância para se traçar estratégias de ensino diferenciadas.

Mesmo com as lacunas ocasionadas por falta de profissionais capacitados para atuarem nos NAPNEs, inexistência de códigos de vagas específicos para professores de AEE e outros profissionais de atendimento aos estudantes com deficiência e/ou outras especificidades, em algumas instituições da Rede há o desenvolvimento do chamado Plano Educacional Individualizado (PEI). O PEl é um processo que prevê a construção conjunta, o trabalho colaborativo, envolvendo não apenas os NAPNEs mas também o setor pedagógico, assistência estudantil, professores, coordenadores de curso, estudantes e seus familiares (RODRIGUES SANTOS, 2020). Assim, os núcleos, realizam diversas atividades, tais como: formação de servidores dos campi, atividades com os alunos, pesquisa, extensão, participação e elaboração de políticas, etc., e além disso, têm participação ativa na escolarização do aluno PAEE.

A proposta de Plano Educacional individualizado, segundo Tannús-Valadão e Mendes (2018), corresponde a um processo documentado, que poderá ser alterado, que irá nortear o percurso e os suportes oferecidos aos estudantes PAEE. Nele são registrados os objetivos, as diferenciações individualizadas para as expectativas de aprendizagem traçadas para o estudante, levando em consideração o currículo padrão escolar, seu repertório de partida, os conhecimentos e habilidades durante o processo. O PEI, em sua concepção, deveria acompanhar o aluno Público-Alvo da Educação Especial que precisa de medidas diferenciadas, em toda a sua escolarização, adentrando possivelmente em sua 
http://dx.doi.org/10.5902/1984686X52842

trajetória profissional. Como esse requisito não é exigido na maioria dos sistemas educacionais brasileiros, e, quando esses planos e registros existem, não chegam, em sua maioria, nas instituições de ensino médio e superior, os PEls acabam sendo desenvolvidos no ingresso do estudante nas instituições da Rede Federal de EPCT, contemplado diferentes protocolos de planejamento.

Rodrigues Santos (2020) identificou protocolos de PEI diferentes nos 37 Institutos pesquisados, que no conjunto continham informações sobre:

Dados sobre a identificação dos estudantes PAEE, elas envolviam informações pessoais do estudante e sua família com questões sobre condições de saúde e informações institucionais pregressas e atuais do estudante. As etapas de elaboração do planejamento envolviam avaliação para elegibilidade do PEI e para identificação do repertório de partida do estudante, reuniões para elaboração e autorização do documento, implementação do plano de ação e processo de avaliação do ensino e aprendizagem, além da revisão do PEl e da elaboração do plano de transição. Identificaram-se lacunas quanto à autorização e garantia de participação efetiva do estudante PAEE e sua família na elaboração do PEI; além da ausência da etapa do plano de transição nos documentos analisados (RODRIGUES SANTOS, 2020, p. 8).

Nos documentos referentes ao PEl deveriam constar também como seria feita a remoção de barreiras mencionadas na Lei 13.146 (BRASIL, 2015) que dialogam com o contexto educacional e com as dimensões de acessibilidade ampliadas discutidas por Sassaki (2009), quais sejam: (a) Arquitetônica: sem barreiras físicas; (b) Comunicacional: sem barreiras na comunicação entre pessoas; (c) Instrumental: sem barreiras nos instrumentos, ferramentas, utensílios; (d) Metodológica: sem barreiras nos métodos e técnicas de lazer, trabalho, educação; (e) Programática: sem barreiras embutidas em políticas públicas, legislações, normas; (f) Atitudinal: sem preconceitos, estereótipos, estigmas e discriminações nos comportamentos da sociedade para pessoas que têm deficiência.

Pensando na atuação da Rede Federal de EPCT, entende-se que além de remover as barreiras específicas da escolarização do ensino técnico e tecnológico, há, muitas vezes, o desafio de suprir as lacunas de escolarização anterior ao ensino médio e superior. Percebe-se, neste cenário, que a sociedade e a escola têm potencializado a deficiência ao atribuir a esta (e apenas a ela) as dificuldades no processo de escolarização dos estudantes, constituindo assim a chamada "deficiência social". Essa situação impõe uma série de desafios que também precisam ser pensados de maneira coletiva no PEI, priorizando sempre a flexibilização de tempo em detrimento à supressão de conteúdos ou 
http://dx.doi.org/10.5902/1984686X52842

de objetivos, além de considerar que as instituições também precisam se reinventar e enxergar suas fragilidades.

Nessa perspectiva, traçar o PEI é pensar nos suportes educacionais e nas estratégias para o rompimento das barreiras impostas aos alunos PAEE, especialmente àqueles que não estejam, ainda, totalmente aptos "a ter as mesmas aprendizagens esperadas dentro do currículo padrão do ano/série que ele/ela frequenta[m]" (TANNÚS-VALADÃO; MENDES, 2018, p. 7).

Defende-se também, que a acessibilidade possa ser pensada com base na concepção do Desenho Universal de Aprendizagem (DUA), que "consiste na elaboração de estratégias para acessibilidade de todos, tanto em termos físicos quanto em termos de serviços, produtos e soluções" (ZERBATO; MENDES, 2018, p. 159-150), podendo ir, segundo as autoras, do todo ao mais individualizado, de maneira que a implementação de algo pensado para todos os discentes da sala possa ser planejado e realizado com diferentes formas de ensino, que atendam os estudantes individualmente.

Alguns alunos poderão necessitar de um apoio individualizado para determinadas atividades, enquanto que para outras não; outros alunos necessitarão de mais tempo para realização de algumas tarefas. O que não pode acontecer no ensino em turmas inclusivas é a utilização da mesma estratégia sempre ou do mesmo recurso/serviço para todos os alunos, sendo "indispensável a avaliação continuada do ensino, da aprendizagem e dos serviços de apoio necessários para cada estudante" (ZERBATO; MENDES, 2018, p. 154). Assim, o pensar coletivo mediado pelos NAPNEs não substituiria, de maneira alguma, o papel do Atendimento Educacional Especializado, da equipe multiprofissional e dos demais atores envolvidos no processo de escolarização dos estudantes.

Diante deste cenário, atinente ao papel do NAPNEs no contexto da Rede de EPCT e à função que eles vêm desempenhado, principalmente em relação à escolarização do aluno, os objetivos desse estudo limitam-se a descrever, analisar e socializar o papel que núcleos de dois Institutos Federais de Educação brasileiros vêm desenvolvendo, além de trazer reflexões sobre o Plano Educacional Individualizado.

\section{Método}

As análises do artigo foram realizadas com o viés qualitativo, em uma pesquisa com técnica documental, que se utiliza "de materiais que não receberam ainda um tratamento analítico, ou que ainda podem ser reelaborados de acordo com os objetivos da pesquisa". 
http://dx.doi.org/10.5902/1984686X52842

(GIL, 2008, p. 51). Foram utilizados arquivos públicos (MARCONES, LAKATOS; 2003), documentos oficiais disponíveis nos sites do IFRS e do IFSP. Os dados foram analisados fazendo uma aproximação entre os dois Institutos estudados, buscando semelhanças e diferenças referentes ao NAPNE e à realização do PEI.

\section{Apresentação das Instituições}

O Instituto Federal de Educação, Ciência e Tecnologia de São Paulo - IFSP possui na configuração atual 37 campi em funcionamento, alguns deles oriundos da antiga "Escola de Aprendizes e Artífices de São Paulo", posteriormente denominada "Liceu Industrial de São Paulo", "Escola Industrial de São Paulo", "Escola Técnica de São Paulo", "Escola Técnica Federal de São Paulo" e "Centro Federal de Educação Tecnológica de São Paulo" (IFSP, 2019, p. 29). Outras unidades são parte de um programa de expansão após 2008, e encontram-se espalhados na região da capital, litoral e interior do estado de São Paulo, alguns classificados como campus avançado.

O Instituto Federal de Educação, Ciência e Tecnologia do Rio Grande do Sul (IFRS) em sua criação, estruturou-se a partir da união de três autarquias federais: o Centro Federal de Educação Tecnológica (CEFET) de Bento Gonçalves, a Escola Agrotécnica Federal de Sertão e a Escola Técnica Federal de Canoas. Logo após, foram incorporados "ao instituto dois estabelecimentos vinculados a Universidades Federais: a Escola Técnica Federal da Universidade Federal do Rio Grande do Sul (UFRGS) e o Colégio Técnico Industrial Prof. Mário Alquati, de Rio Grande" (IFRS, 2020a, p. 1). No decorrer do processo "unidades de ensino técnico nos municípios de Farroupilha, Feliz e Ibirubá foram federalizadas e criados os campi de Caxias do Sul, Erechim, Osório e Restinga. Estas instituições hoje fazem parte do IFRS na condição de campi (IFRS, 2020a, p. 1), que atualmente totalizam 17 campis.

De acordo com dados de 2019, o IFRS possuía aproximadamente de 27 mil alunos, 200 opções de cursos, 1.150 professores e 990 técnicos-administrativos (IFRS, 2020a).

O IFSP também possui 200 opções de cursos; em 2020 contabilizava cerca de 50 mil alunos em curso, e, aproximadamente 49 mil estudantes, 2.572 docentes e 1.841 técnicosadministrativos (IFSP, 2019).

\section{Papel dos núcleos no IFRS e no IFSP}

A proposta de inclusão e acessibilidade do IFRS estrutura-se a partir de instâncias representativas na reitoria e nos campi. A Assessoria de Ações Afirmativas, Inclusivas e 
http://dx.doi.org/10.5902/1984686X52842

Diversidade, vinculada ao reitor (IFRS, 2017a; IFRS, 2018a) e institucionalizada pela Reitoria por meio da Portaria 51/2012, "é o órgão responsável pelo planejamento e coordenação das ações relacionadas à política de inclusão no IFRS" (IFRS, 2020b, p 1). Ainda na reitoria, vinculada à Pró-reitoria de Ensino, o Centro Tecnológico de Acessibilidade é o setor responsável por propor, orientar e executar ações de ensino, pesquisa, desenvolvimento e extensão "em acessibilidade arquitetônica, instrumental, comunicacional, programática, metodológica, atitudinal e recursos de tecnologia assistiva no IFRS" (IFRS, 2020b, p.1). Nos campi fase I e II da instituição existem os NAPNEs (Núcleos de Atendimento às Pessoas com Necessidades Educacionais Específicas), institucionalizados por meio da Resolução oㅡ 20/2014 como sendo "um setor propositivo e consultivo que media a educação inclusiva na instituição" (IFRS, 2014, p. 1). No caso dos campi fase III, consideradas unidades em implantação, e também na reitoria, os Núcleos de Ações Afirmativas (NAAfs), correspondem a um "setor propositivo e consultivo que media as ações afirmativas na instituição", congregando assim as ações dos "NAPNEs, Núcleos de Estudos Afro-brasileiros e indígenas - NEABls e Núcleos de Estudos e Pesquisa em Gênero e Sexualidade - NEPGSs" (IFRS, 2017b, p. 1). Os NAAfs foram institucionalizados por meio da Resolução oㅜ 38/2017 (IFRS, 2017b).

No IFSP, até 2019 havia vinculada a Pró Reitoria de Ensino a Assessoria de Ações Inclusivas, que passou a compor as ações do Departamento de Articulação Pedagógica, Ações Inclusivas e Formação Continuada (DAPE-PRE) até 2020, quando foi recém criada uma diretoria de núcleos vinculada ao gabinete do reitor, com o objetivo de "ampliar as ações desenvolvidas pelos núcleos vinculados à reitoria, aumentar a atenção para suas pautas e propiciar comunicação mais ágil com as pró-reitorias" (IFSP, 2020). Porém, essa medida, em processo de efetivação, gerou questionamentos pois foi adotada sem participação do Núcleo de Estudos Afro-brasileiros e Indígenas (NEABI), o Núcleo de Estudos em Gênero e Sexualidade (NUGS) e o Núcleo de Apoio às Pessoas com Necessidades Educacionais Específicas (NAPNE).

O NAPNE do IFSP foi regulamentado em 2014, através da resolução 137, com previsão de núcleos implantados em cada campi. Diante do pressuposto dos núcleos estão: 
I. Criar a cultura da educação para a convivência, o respeito à diversidade, a promoção da acessibilidade arquitetônica, bem como a eliminação das barreiras educacionais e atitudinais, incluindo socialmente a todos por meio da educação;

II. Prestar apoio educacional aos estudantes com deficiência, com transtorno do espectro autista e com altas habilidades/superdotação do campus;

III. Difundir e programar as diretrizes de inclusão dos estudantes com deficiência, com transtorno do espectro autista e com altas habilidades/superdotação no campus;

IV. Integrar os diversos segmentos que compõem a comunidade escolar para desenvolver sentimento de corresponsabilidade na construção da ação educativa de inclusão no IFSP;

V. Promover a prática democrática e as ações inclusivas para estudantes com deficiência, com transtorno do espectro autista e com altas habilidades/superdotação como diretrizes do campus. (IFSP, 2014, p. 3-4)

Em relação ao público-alvo, a Resolução 137/2014 do IFSP define no seu artigo Art. $6^{\circ}$, que "constitui-se público-alvo das ações inclusivas do NAPNE de cada campus os estudantes com necessidades educacionais específicas que se originam em função de deficiência, transtorno do espectro autista e de altas habilidades/superdotação" (IFSP, 2014 , p. 3-4). No IFRS o público atendido são os denominados estudantes com necessidades educacionais específicas, ou seja: aqueles cujas necessidades educacionais se originam em função de deficiências, de altas habilidades/superdotação, transtorno do espectro autista e outros transtornos de aprendizagem (IFRS, 2014).

A discussão sobre o público atendido, todavia, é presente no contexto do IFSP e dos núcleos em geral, em virtude da orientação inicial pelo Programa TECNEP de que o núcleo trabalharia com as "necessidades específicas", com um público ampliado além do tradicional PAEE. Nesse contexto, mesmo com a definição de público, sabe-se que são realizados PEls para alunos com outras necessidades educacionais, como questões de ordem psicológica, limitações referentes à fala, dentre outras. Porém, parte-se do pressuposto de que essa realidade deve ser avaliada em cada campi, considerando-se a estrutura do núcleo e da Coordenadoria Sociopedagógica, que, com a equipe multiprofissional, poderia atuar com os outros públicos, inclusive possibilitando o desenvolvimento do PEI. O debate sobre o PAEE também é frequente na revisão da Política Nacional de Educação Especial, sempre tencionando a possibilidade de ampliação de público no documento que está em tramitação no MEC.

Em relação à composição básica no IFSP, está prevista a participação da equipe multiprofissional, que são parte da Coordenadoria Sociopedagógica do campus, constituída por: pedagogo, assistente social, psicólogo e técnico em assuntos educacionais. $\mathrm{O}$ documento afirma que: 
http://dx.doi.org/10.5902/1984686X52842

[...] podem participar outros servidores do IFSP (docentes e técnicos administrativos) e pessoas da comunidade escolar (direção-geral, docentes, técnicos-administrativos, estudantes e familiares) que se identificam com a temática da inclusão, manifestam o desejo de participação no NAPNE e se dispõem a incorporarem-se nos projetos de inclusão e a desenvolver as ações da educação inclusiva no campus. (IFSP, 2014, p. 4)

Essa composição básica tem restringido as equipes do NAPNE de alguns campi em Coordenadoria Sociopedagógica, que, pelo fato de desempenharem diferentes funções, acabam suprindo as demandas relacionadas aos objetos dos NAPNEs. Diante disso sugere-se, no que se refere à composição do núcleo, que seja alterada a orientação de "podem participar" para "sugere-se a participação de docentes, técnico administrativos, estudantes e familiares". Outro apontamento refere-se à inexistência de referência a profissionais como: tradutor-intérprete de Libras, docente de Libras, professor de Educação Especial, Profissional de Apoio, Braillista, Guia Vidente, Ledor, dentre outros.

No que se refere aos NAPNEs no IFRS, apesar de a comunidade interna estar ciente da importância do papel desses núcleos, não há uma composição básica, mas sim a figura de um Coordenador/Presidente, Secretário e seus respectivos suplentes. Também podem compor o núcleo outros servidores, estudantes e integrantes da comunidade externa. É garantido, por meio da Resolução no 20/2014, oito horas semanais ao Coordenador/Presidente e quatro horas semanais ao Secretário para se dedicarem ao núcleo, quantidade essa demonstrada insuficiente diante da demanda crescente de trabalho dos NAPNEs. Cabe ao diretor geral de cada campus institucionalizar o núcleo e seus integrantes por meio de portaria.

Além do supramencionado também não é prevista para o NAPNE do IFSP e nem do IFRS uma coordenação, em virtude de não existir função gratificada para quem preside o núcleo, que, no caso do IFSP é nomeado como "Representante", eleito a cada dois anos junto com um secretário. Com uma carga horária de trabalho prevista de "6 (seis) horas semanais", esse servidor tem como atribuições:

I. Coordenar as reuniões do NAPNE;

II. Convocar as reuniões ordinárias e extraordinárias do NAPNE;

III. Assinar os documentos expedidos pelo NAPNE, juntamente à DireçãoGeral e à Gerência Educacional ou setor equivalente do campus;

IV. Zelar pelo bom andamento dos trabalhos desenvolvidos pelo NAPNE;

V. Representar o NAPNE do campus nas ocasiões em que se fizer necessário;

VI. Redigir documentos e relatórios do NAPNE do campus, quando necessário;

VII. Disseminar ao NAPNE do campus conhecimentos adquiridos por meio de capacitações, de formações continuadas e de participações em eventos de educação inclusiva. (IFSP, 2014, p. 4) 
Mesmo sendo prevista uma formação realizada pelo Coordenador/Representante do núcleo, que deve ser "disseminada", muitos desses servidores que compõem a equipe dos dois institutos estudados não possuem formação em Educação Especial, nem assumem a função de docente com formação específica, que teriam como pressuposto de sua atuação "VIII. Assessorar aos docentes do campus quanto ao processo educacional inclusivo" (IFSP, 2014, p. 4). Defende-se aqui, valorizando o trabalho desenvolvido pelos NAPNEs do IFSP, que é desafiante exercer essa função, o qual, exigiria mais do que seis horas semanais para esse assessoramento, seja em forma de consultoria colaborativa ou de coensino, considerando número de alunos PAEE de cada campus.

Em relação às competências, algumas são inquietantes, como por exemplo

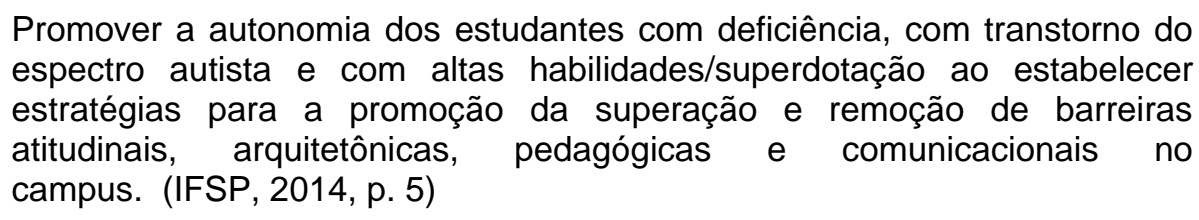

Com a estrutura atual do apoio, luta-se para autonomia, mas sabe-se que ainda faltam, além de recursos humanos já mencionados, recursos materiais e de tecnologia assistiva, como Impressoras Braille, lupas, teclados colmeias, punções, etc. - recursos que foram garantidos às escolas que participaram do programa de implantação das Salas de Recursos Multifuncionais pelo MEC.

Outras competências do núcleo do IFSP que merecem destaque são

II. Mediar as relações entre as famílias, o campus e as instituições especializadas que atendam os estudantes com necessidades educacionais específicas que se originam em função de deficiência, de transtorno do espectro autista e de altas habilidades/superdotação.

III. Estabelecer parcerias do campus com as instituições especializadas e com a rede de serviços públicos municipal, estadual e federal, para atendimento dos estudantes público alvo da educação especial. (IFSP, 2014, p. 5)

Assim, parte-se do pressuposto de que o Atendimento Educacional Especializado seria realizado por outra instituição e não no contexto do IFSP, como orientado na Política Nacional de Educação Especial (2008). Fato esse alterado, todavia, somente no PDI, quando prevê, entre 2019- 2023. 
http://dx.doi.org/10.5902/1984686X52842

a acessibilidade física para pessoas com deficiência ou mobilidade reduzida; a realização da semana da diversidade, em todos os câmpus, anualmente, a promoção de debates sobre diversidade nos currículos; a acessibilidade virtual/comunicacional de sites, portais, sistemas e ambientes virtuais de ensino-aprendizagem; a disponibilização de produtos e serviços de Tecnologia Assistiva para o apoio ao público-alvo da educação especial; a disponibilização de intérprete de Libras para estudantes surdos ou com deficiência auditiva, conforme a demanda e necessidade de atendimento, durante todo o percurso educacional; a disponibilização de guia-intérprete para estudante surdocego, durante todo o percurso educacional; a implantação de salas de recursos multifuncionais nos Câmpus do IFSP, conforme a demanda e necessidade de atendimento e a oferta de atendimento educacional especializado (AEE) aos estudantes público-alvo da educação especial que demandarem esse atendimento (IFSP, 2019, p. 241242)

Algumas ações destinadas ao núcleo fortalecem as propostas de ensino, pesquisa e extensão e são encontradas nos relatórios anuais dos campis do IFSP publicados nosúltimos cinco anos nas Revistas NAPNE em Ação ${ }^{7}$, que se diferenciam em cada campi, principalmente pela formação e possibilidades da equipe que faz parte do núcleo. As ações a serem propostas compactuam com as dimensões de acessibilidade pontuadas por Sassaki (2009) e com a LBI (BRASIL, 2015).

Vale mencionar que para essas ações não existe previsão orçamentária como política do IFSP para aquisição de materiais, recursos de tecnologia assistiva, mobiliário, de cada campi. Também não existe orientação para que seja destinada verba, ficando a critério do diretor e dos órgãos colegiados do campus a possibilidade do financiamento. Outra questão é que as propostas das parcerias deveriam ter fortalecimento via extensão, mas que essas não podem se responsabilizar por ações específicas da instituição, como oferecer recursos próprios para acessibilidade, conforme apontada na LBI (2015).

\section{Orientação para o PEl segundo os documentos oficiais}

Em março de 2017 o IFSP publicou a Instrução Normativa PRE/IFSP no 001, de 20 de março, com as orientações para "identificação e acompanhamento, pelo NAPNE, do estudante com necessidades específicas". A resolução indica que a identificação do estudante pode acontecer no ato da matrícula ou em qualquer tempo, pelos docentes, servidores, estudante, com o laudo médico; e na ausência desse, a necessidade específica deve ser avaliada pelo NAPNE. O IFSP, todavia, não tem a previsão da avaliação biopsicossocial como prevê a LBI (BRASIL, 2015). Também é previsto o acompanhamento do NAPNE em uma "necessidade específica temporária no decorrer do curso e, conforme o caso, também deve ser apoiado pelo NAPNE" (IFSP, 2017, p. 2). A resolução indica que 
http://dx.doi.org/10.5902/1984686X52842

se inicie um trabalho para conhecer os estudantes, suas necessidades e a interlocução com os servidores:
a) identificação da situação pela equipe e entendimento da demanda;
b) conversa inicial com o estudante;
c) reuniões/entrevistas com pais, responsáveis ou familiares;
d) levantamento de dados pedagógicos, como frequência, participação nas atividades do curso, interação com a turma e desempenho (avaliações/notas);
e) reuniões com docentes e equipe pedagógica do câmpus;
f) reuniões com outros profissionais envolvidos com a situação do estudante;
g) contato com instituições que o estudante frequentou anteriormente, se necessário;
h) contato com instituições específicas, de acordo com o caso. (IFSP, 2017, p. 3).

Destaca também que o acompanhamento deve ter a concordância do aluno e seus familiares, caso sejam menores de idade e que

\begin{abstract}
Art. 8o. É importante que a situação acadêmica dos estudantes com necessidades específicas seja analisada nas reuniões de cursolárea, assim como nos Conselhos de Classe (sem a presença de estudantes ou pais/responsáveis), de forma a serem verificadas as possibilidades e encaminhamentos do processo de ensino e aprendizagem do discente. (IFSP, 2017, p. 5).
\end{abstract}

O Art. 5o. trata do nomeado "Plano Educacional Individualizado (PEI)", que "consiste em um documento que contém as informações sintetizadas, obtidas pela CSP e NAPNE, assim como o planejamento do trabalho pedagógico a ser desenvolvido." (IFSP, 2017, p. 4). Tannús-Valadão e Mendes (2018) entendem que o processo que culminaria no documento deveria ser mais do que um simples "sistematizar de informações", mas sim ter como propósitos criar metas, objetivos, tendo o estudante como o principal debatedor do plano, pois é para ele que esse caminho seria traçado. Nesse movimento, o estudante não daria somente a anuência, mas seria parte da elaboração: o documento deve ser elaborado em reuniões coletivas, com a presença dos docentes que ministram/ ministrarão aulas para esses alunos, coordenador de curso, NAPNE, aluno, e familiares, se o aluno for menor de idade. Especialistas externos, monitores, estagiários e demais profissionais envolvidos são essenciais para trocar as informações durante a reunião.

Documentar as ações e diferenciações desenvolvidas para o aluno PAEE nos ajuda enquanto instituição a pensar em novas estratégias para esse e para futuros alunos. O PEI é mais do que o preenchimento do próprio formulário, mas todo processo de pensar nas medidas possíveis para garantir o direito do aluno de ter acesso ao conhecimento. Fortalece também a instituição na solicitação de profissionais para atuar com esse aluno, 
http://dx.doi.org/10.5902/1984686X52842

equipamentos, reformas, dentre outros. Diante do supramencionado, orienta-se que o documento seja elaborado com três partes, que correspondem às informações gerais do estudante, os encaminhamentos sugeridos pela CSP e pelo NAPNE, e o programa pedagógico docente. O anexo do documento traz uma sugestão de roteiro de preenchimento por campi, porém, não existe menção da base teórica ou das referências usadas na construção dessa proposta, que inicia com a descrição das informações gerais do estudante:

Na primeira parte, haverá informações gerais sobre o estudante, sobre sua trajetória acadêmica e pessoal e seu perfil, tais como: nome; idade; curso, turma, interesses; habilidades, dificuldades; fatores do ambiente físico, social, atitudinal que influenciam de forma positiva ou negativa (barreiras/dificuldades); se necessário, os elementos de apoio oferecidos pela família, profissionais clínicos e outros atendimentos/ tratamentos/ encaminhamentos, entre outras informações. (IFSP, 2017, p. 4)

O documento sugere também que se destaque os "Processos metodológicos e avaliativos já realizados com resultados satisfatórios", que, sugere-se que em uma primeira versão do PEl busque-se informações com o estudante e a escolarização anterior: finalizando a parte I com "Outras informações relevantes (Se necessário, indicar de forma sucinta elementos de apoio oferecidos pela família, profissionais clínicos e outros atendimentos/ tratamentos/ encaminhamentos)" (IFSP, 2017, p. 10).

A parte "II. Encaminhamentos sugeridos / adaptações" traz seis tópicos relacionados a medidas que constam nos Parâmetros Curriculares Nacionais (1998): "1. adequações organizativas: facilitam o processo educativo; 2. adequações aos objetivos: expectativas de aprendizagem; 3. adequações aos conteúdos: expectativas de aprendizagem; 4. adequações metodológicas: procedimentos didáticos; 5. adequações avaliativas e 6 . adequações à temporalidade" (p. 11-12).

ENCAMINHAMENTOS SUGERIDOS - A segunda parte será composta pelas ações sugeridas pela CSP e NAPNE, coordenador de curso, docentes, em conjunto com outros profissionais, familiares, quando for o caso, e o próprio estudante, envolvendo as adaptações/adequações necessárias: organizativas, dos objetivos do curso/das disciplinas (expectativas de aprendizagem), dos conteúdos (conhecimentos, procedimentos e atitudes), metodológicas, avaliativas e em relação à temporalidade. Tem como objetivo identificar as necessidades e ações a serem implementadas, como também possíveis atividades extras a serem desenvolvidas e o trabalho de integração com a turma, quando necessário. (IFSP, 2017, p. 4)

As etapas de PEI proposta por Tannús-Valadão (2011) não são contempladas na orientação do PEI do IFSP. É prevista uma avaliação sobre a necessidade do PEI, porém 
http://dx.doi.org/10.5902/1984686X52842

a realização da avaliação tem tido como foco as experiências anteriores e a necessidade de acessibilidade, mas faltam indicativos sobre questões relacionadas ao conteúdo. Também não é previsto no documento, apesar de essa ser a orientação para os campi, a preparação e a reunião do PEl de maneira coletiva. Existem indicativos de atualização do Plano, mas não encontradas orientações de como deve ser realizado. Tannús-Valadão (2014), falando especificamente do PEI, ressalta que

\begin{abstract}
Um dos benefícios do PEI consiste em trazer para a escolarização do estudante um compromisso documentado dos responsáveis por ele, sendo esse compromisso uma espécie de contrato que deverá ser cumprido, no mínimo, em um ano. Esse benefício aumenta a responsabilidade da escola e dos familiares para uma prestação de contas sobre o processo de ensino aprendizagem, tornando os horários para planejamento coletivos e individuais essenciais para que seja cumprido esse contrato. (TANNÚSVALADÃO; MENDES, 2014, p. 93)
\end{abstract}

No documento do IFSP, existe apenas a previsão de que "o PEI precisará ser avaliado continuamente, de forma a ser reformulado sempre que houver necessidade". (IFSP, 2017. p. 5). Sugere-se também a análise das "atividades extras a serem desenvolvidas Atendimento individualizado pelo professor, Apoio Pedagógico, Monitoria, Recuperação..." (IFSP, 2017 p. 12) e "Trabalho de integração do(a) estudante com a turma (quando for o caso)" (IFSP, 2017, p. 12). Não são previstas ações com profissionais especializados, atendimento na sala de recursos multifuncionais, profissional de apoio, guia intérprete, dentre outros.

O item "III. Programa Pedagógico" tem relação direta com o Componente(s) Curricular(es), sugerindo que seja preenchido individualmente por cada professor. O arquivo direciona os docentes para repensarem seus objetos específicos, conteúdos, metodologias e forma de avaliação.

III. PROGRAMA PEDAGÓGICO - Na terceira etapa, serão delineados, pelos professores, em conjunto com a CSP e NAPNE, as adequações/adaptações a serem realizadas e, mais especificamente, os objetivos das disciplinas e os respectivos saberes a serem construídos (conteúdos), assim como as metodologias específicas e os processos avaliativos (procedimentos / critérios / instrumentos) diferenciados.

Mais uma vez é importante afirmar que os docentes, em sua maioria, não dispõem de profissionais com formação específica em educação especial para trocar e planejar seus objetivos específicos, metodologias, formas de avaliação, etc., destacando-se a importância do NAPNE nesse processo, mas valorizando a falta da formação para garantir o "pleno acesso ao currículo em condições de igualdade" (LBI, 2015, p. 6). 
http://dx.doi.org/10.5902/1984686X52842

O documento prevê no Art. 7o. que "Em todo o processo, deverão ser previstas formas de mensuração do progresso do estudante, em uma avaliação contínua que analise os saberes desenvolvidos e os encaminhamentos necessários para o prosseguimento dos estudos", porém não existem, na sugestão de roteiro, indicações de como deverá ser realizado. (IFSP, 2017).

No caso do IFRS no que tange aos procedimentos para prover acessibilidade curricular, ou seja: estratégias pautadas em um currículo na perspectiva da acessibilidade (CABRAL, 2020), aos alunos com necessidades educacionais específicas, foram institucionalizados, por meio da Instrução Normativa $n$ ำ12/2018, os fluxos e procedimentos para identificação, acompanhamento e realização do $\mathrm{PEI}$ dos estudantes com necessidades educacionais específicas:

$\S 2$ O PEl é um recurso pedagógico com foco individualizado no estudante e tem por finalidade otimizar o processo de ensino e aprendizagem de pessoas com deficiência ou outras especificidades. É um registro das adaptações individualizadas que são necessárias para o estudante alcançar as expectativas de aprendizagem definidas para ele, no qual deve haver registro dos conhecimentos e habilidades prévios que identificam o repertório de partida, acompanhar a evolução em direção aos objetivos, e traçar novas estratégias de ensino e aprendizagem. É uma proposta pedagógica compartilhada, que deve ser construída de forma colaborativa pelos profissionais da instituição de ensino, pais e/ou responsáveis e, quando possível, pelo próprio estudante (IFRS, 2018b, p. 1).

Para viabilizar a implementação desses procedimentos, setor pedagógico, assistência estudantil, NAPNEs (ou NAAfs), coordenadores de curso e docentes de cada componente curricular, a partir de um trabalho colaborativo e da escuta aos estudantes, familiares e profissionais de apoio, desenvolvem o instrumento para cada estudante que necessitar de alguma flexibilização curricular, seja no acesso ao currículo como aos elementos do mesmo.

O ponto de partida são as informações pregressas desse estudante e, a partir delas, a definição das estratégias de acessibilidade de acordo com as especificidades de cada um. O processo de coleta das informações iniciais inicia-se pela família, onde são colhidos os dados pessoais do estudante, a forma de comunicação, interação, dificuldades, potencialidades, interesses, como ele aprende melhor, se faz uso de tecnologia assistiva e outras informações que se façam necessárias de acordo com as especificidades de cada estudante. 
http://dx.doi.org/10.5902/1984686X52842

Outra fonte de informação pertinente refere-se à rede de profissionais de apoio, caso o estudante faça atendimentos por profissionais da saúde ou outros, é importante conhecer o que é feito.

Acerca da instituição pregressa busca-se informações acerca da existência ou não de professor de AEE, SRM, metodologia e formas de avaliação, estratégias pedagógicas, melhores resultados, potencialidades e dificuldades demonstradas pelo estudante.

Torna-se salutar a coleta das informações com todos esses atores acerca da necessidade educacional específica do estudante, das atitudes mais pertinentes perante esse aluno, melhores possibilidades de flexibilizações, estratégias que deram certo no que tange à acessibilidade curricular. Tais procedimentos passam pela remoção das diversas barreiras de acessibilidade e vão desde a acessibilidade física, o uso de tecnologia assistiva $^{8}$, a produção de materiais didático-pedagógicos acessíveis até as adequações de tempos, espaços, flexibilizações metodológicas, propostas diferenciadas de avaliação, dentre outras. Todas essas informações, bem como o registro das adequações, estratégias e metodologias devem ser explicitadas no Plano Educacional Individualizado do estudante ${ }^{9}$.

Após realizada a coleta dessas informações pelo setor pedagógico, assistência estudantil e NAPNE/NAAf, todo esse arcabouço informativo do estudante passa a ser apresentado e discutido em reunião com os docentes, que por meio de um trabalho colaborativo, prosseguem no preenchimento do PEI agora com dados específicos de seu componente curricular e das flexibilizações curriculares que se fizerem necessárias.

\section{Considerações finais}

É inegável a importância e o papel que os NAPNEs têm desempenhado no contexto da Rede Federal de Educação Profissional e Tecnológica, não somente na escolarização do aluno PAEE, mas em ações de pesquisa, ensino e extensão. Ações como essas têm beneficiado não só os estudantes com deficiência, TEA, altas habilidades e superdotação, mas também aqueles com outras necessidades educacionais específicas e a comunidade escolar em geral, na medida que trazem para o debate a importância de se viver e de se caminhar para uma sociedade equânime e justa.

A existência do Núcleo, entretanto, no contexto da educação básica, profissional e tecnológica, não pode suprimir a necessidade e a garantia legal que os estudantes possuem de contar com os outros Serviços de Apoio da Educação Especial, sendo eles o AEE, o Tradutor Intérprete de Libras, Audiodescritor, Ledor, equipe multidisciplinar, dentre 
http://dx.doi.org/10.5902/1984686X52842

outros. Isso significa que lutar pela garantia dos outros serviços não enfraquece a força do Núcleo, ao contrário, fortalece sua composição e seus objetivos, ao complementar e ampliar os outros serviços garantidos.

Assim, o espaço do NAPNE deve ser o espaço de organização do PEI, pois ele tem tido o papel de reunir os diferentes setores e a comunidade escolar. Entretanto, não pode ser de responsabilidade exclusiva deste Núcleo a organização de todo o processo, que requer um trabalho coletivo e colaborativo entre todos os atores envolvidos, que precisam estar em concordância com as metas e objetivos traçados no $\mathrm{PEI}$, pois todos são responsáveis pelas suas ações.

Entende-se, partindo dos objetivos e da proposta do Núcleo, que é necessário fortalecê-los, tornando-os setores que efetivamente tenham condições de atuar em prol da acessibilidade curricular e que sejam espaços de decisão. É imprescindível que os NAPNEs sejam setores estratégicos dentro da instituição, com servidores capacitados e dedicados exclusivamente às ações do Núcleo, além de disporem de uma coordenação específica. Ressalta-se também a necessidade de se destinar recursos para viabilizar a aquisição e o desenvolvimento de tecnologia assistiva, além de prover as diversas dimensões de acessibilidade.

Outro fator importante nesse contexto é a realização de pesquisas que tratem de temáticas relacionadas à inclusão na Rede Federal de Educação Profissional e Tecnológica, além da sistematização de dados oficiais sobre o acesso, permanência, êxito e conclusão dos estudantes PAEE, sendo essa a base para luta da efetivação das políticas públicas já garantidas e pelo direcionamento das que ainda devem ser elaboradas.

Os dados analisados aqui, cujo foco de estudo foi avaliar como as propostas de atuação dos NAPNEs e da elaboração dos PEls têm sido pensadas, especialmente no contexto do IFRS e IFSP, deixam, como desdobramento para estudos futuros, o contexto nacional dos processos de inclusão educacional e de estratégias exitosas da Rede que possam ser replicadas em outros tempos e espaços, tendo como meta a efetiva implementação da acessibilidade curricular. 
http://dx.doi.org/10.5902/1984686X52842

\section{Referências}

BRASIL. Ministério da Educação. Política Nacional de Educação Especial na perspectiva da educação Inclusiva. Brasília: MEC, 2008a. Disponível em:

http://portal.mec.gov.br/index.php?option=com_docman\&view=download\&alias=16690-

politica-nacional-de-educacao-especial-na-perspectiva-da-educacao-inclusiva-

05122014\&Itemid=30192. Acesso em: 20 jun. 2020.

BRASIL. Lei no 13.146, de 6 de julho de 2015. Institui a Lei Brasileira de Inclusão da Pessoa com Deficiência (Estatuto da Pessoa com Deficiência). Brasília, 2015. Disponível em:

http://www.planalto.gov.br/ccivil_03/_ato2015-2018/2015/lei//13146.htm. Acesso em: 15 jun. 2020.

BRASIL. Lei no 12.711, de 29 de agosto de 2012. Dispõe sobre o ingresso nas universidades federais e nas instituições federais de ensino técnico de nível médio e dá outras providências. Disponível em: http://www.planalto.gov.br/ccivil_03/_Ato20112014/2012/Lei/L12711.htm. Acesso em: 17 jun. 2020.

CABRAL, Leonardo Santo Amâncio. Diferenciação e Acessibilidade Curricular na Educação Superior: operacionalidades e desafios in Webnar dos Institutos Federais de Educação Superior e Tecnológica, IFSP - São Carlos, 2020. Disponível em: https://www.idea.ufscar.br/arquivos/comunicacao-social/diferenciacao-e-acessibilidadecurricular-na-educacao-superior.pdf. Acesso em: 2 ago. 2020.

INSTITUTO FEDERAL DE EDUCAÇÃO, CIÊNCIA E TECNOLOGIA DE SÃO PAULO. Resolução 137, de 4 de novembro de 2014. Aprova o Regulamento do Núcleo de Apoio às Pessoas com Necessidades Educacionais Específicas - NAPNE. São Paulo: IFSP, 2014. Disponível em: https://ifsp.edu.br/ex-alunos/42-assuntos/ensino/1472-acoesinclusivas Acesso em: 20 jun. 2020.

INSTITUTO FEDERAL DE EDUCAÇÃO, CIÊNCIA E TECNOLOGIA DE SÃO PAULO. Instrução Normativa PRE 001, de 20 de março de 2017. Estabelece orientações para identificação e acompanhamento pelo NAPNE, dos estudantes com necessidades específicas. São Paulo: IFSP, 2017. Disponível em: https://ifsp.edu.br/ex-alunos/42assuntos/ensino/1472-acoes-inclusivas Acesso em: 20 jun. 2020.

INSTITUTO FEDERAL DE EDUCAÇÃO, CIÊNCIA E TECNOLOGIA DE SÃO PAULO. Plano de desenvolvimento institucional 2019-2023. São Paulo: IFSP, 2019. Disponível em: https://www.ifsp.edu.br/images/pdf/PDI1923/PDI-2019-2023_Aprovado-CONSUP_ 12.03.2019-valendo.pdf Acesso em: 27 jun. 2020.

INSTITUTO FEDERAL DE EDUCAÇÃO, CIÊNCIA E TECNOLOGIA DO RIO GRANDE DO SUL - IFRS, 2014. Resolução no 22/2014. Aprova o Regulamento dos Núcleos de Atendimento às Pessoas com Necessidades Educacionais Específicas do IFRS. Disponível em: https://ifrs.edu.br/wp-content/uploads/2017/09/Resolucao-20-14.pdf. Acesso em: 28 jul. 2020.

INSTITUTO FEDERAL DE EDUCAÇÃO, CIÊNCIA E TECNOLOGIA DO RIO GRANDE DO SUL - IFRS, 2017a. Regimento Geral do IFRS. Disponível em: https://ifrs.edu.br/wpcontent/uploads/2019/01/Regimento_Geral_dezembro_2018.pdf. Acesso em: 29 jul. 2020. 
INSTITUTO FEDERAL DE EDUCAÇÃO, CIÊNCIA E TECNOLOGIA DO RIO GRANDE DO SUL - IFRS, 2017b. Resolução oㅡ 38/ 2017. Aprova o Regulamento dos Núcleos de Ações Afirmativas do IFRS. Disponível em: https://ifrs.edu.br/wpcontent/uploads/2017/08/2017523133111737resolucao_038_17_completa.pdf. Acesso em: 28 jul. 2020.

INSTITUTO FEDERAL DE EDUCAÇÃO, CIÊNCIA E TECNOLOGIA DO RIO GRANDE DO SUL - IFRS, 2018a. Regimento da Reitoria do IFRS. Disponível em:

https://ifrs.edu.br/wp-

content/uploads/2019/01/Regimento_Reitoria_IFRS_Final_Dezembro.pdf Acesso em: 29 jul. 2020.

INSTITUTO FEDERAL DE EDUCAÇÃO, CIÊNCIA E TECNOLOGIA DO RIO GRANDE DO SUL - IFRS, 2018b. Instrução Normativa no 12 de 21 de dezembro de 2018.

Regulamenta os fluxos e procedimentos de identificação, acompanhamento e realização do Plano Educacional Individualizado (PEI) dos estudantes com necessidades educacionais específicas do IFRS. Disponível em: https://ifrs.edu.br/wpcontent/uploads/2018/12/IN-PEl-21.12_Publicada_em_271218.pdf. Acesso em: 28 jul. 2020.

INSTITUTO FEDERAL DE EDUCAÇÃO, CIÊNCIA E TECNOLOGIA DO RIO GRANDE DO SUL - IFRS, 2020a. História do IFRS. Disponível em:

https://ifrs.edu.br/institucional/teste/. Acesso em: 28 jul. 2020.

INSTITUTO FEDERAL DE EDUCAÇÃO, CIÊNCIA E TECNOLOGIA DO RIO GRANDE DO SUL - IFRS, 2020b. Assessoria de Ações Afirmativas, Inclusivas e Diversidade. Disponível em: https://ifrs.edu.br/ensino/assessoria-de-acoes-inclusivas/assessoria-deacoes-inclusivas-aai/. Acesso em: 28 jul. 2020.

NASCIMENTO, Franclin Costa do.; MARTINS, I. C.; BUGARIM, M. C.; MARTINS, A. A Ação TECNEP - Tecnologia, Educação, Cidadania e Profissionalização para Pessoas com Necessidades Específicas como ferramenta de inclusão nas Instituições Federais de Educação Profissional e Tecnológica. Inter Science Place: revista científica internacional, v. 1, ano 4, n. 18, jul./set. 2011. Disponível em:

http://www.interscienceplace.org/isp/index.php/isp/article/view/175. Acesso: 02 jun. 2020.

NASCIMENTO, Franclin Costa do; PORTES, Rutileia M. L. A inclusão de pessoas com necessidades específicas na rede federal de educação profissional, científica e tecnológica, a partir da Ação TEC NEP: uma reflexão atual. In: BRANCHER, V. R.; MEDEIROS, B. de A. (Org.) Inclusão e diversidade: repensando saberes e fazeres na educação profissional, técnica e tecnológica. Jundiaí: Paco Editorial, 2016

RODRIGUES SANTOS, Jéssica. Inclusão escolar e os modos de planejamento educacional individualizado nos Institutos Federais brasileiros Dissertação (Mestrado) - Universidade Federal de São Carlos, Campus São Carlos, São Carlos 2020 . 
http://dx.doi.org/10.5902/1984686X52842

SASSAKI, Romeu Kazumi. Inclusão: acessibilidade no lazer, trabalho e educação.

Revista Nacional de Reabilitação (Reação), São Paulo, Ano XII, mar./abr. 2009, p. 1016.

SONZA, A.; et. al. AFIRMAR a inclusão e as diversidades no IFRS: ações e reflexões. Disponível em: https://cta.ifrs.edu.br/afirmar-a-inclusao-e-as-diversidades-no-ifrs-acoes-ereflexoes/. Acesso em: 20 jul. 2020.

TANNÚS-VALADÃO, Gabriela.; MENDES, Enicéia Gonçalves. Inclusão escolar e o planejamento educacional individualizado: estudo comparativo sobre práticas de planejamento em diferentes países. Revista Brasileira de Educação, v. 23 e230076, 2018. Disponível em: http://www.scielo.br/scielo.php?script=sci_abstract\&pid=S1413$24782018000100261 \&$ Ing=en\&nrm=iso\&tlng=pt. Acesso em: 15 jun. 2020.

VILARONGA, Carla Ariela Rios; MENDES, Enicéia Gonçalves. Ensino colaborativo para o apoio à inclusão escolar: práticas colaborativas entre os professores. Rev. Bras. Estud. Pedagog., Brasília, v. 95, n. 239, p. 139-151, Apr. 2014. Disponível em: http://www.scielo.br/scielo.php?script=sci_arttext\&pid=S2176$66812014000100008 \&$ Ing=en\&nrm=iso. Acesso em: 30 jun. 2020.

ZERBATO, A. P.; MENDES, E. G. Desenho universal para a aprendizagem como estratégia de inclusão escolar. Educação Unisinos, v. 22, 147-155, 2018.

\section{Notas}

${ }^{1}$ A Rede Federal de EPCT utiliza comumente o termo "Educação Inclusiva" por abarcar, para além de estudantes PAEE, aqueles com alguma outra necessidade educacional específica.

${ }^{2}$ A Rede Federal de Educação Profissional Científica e Tecnológica (RFEPCT) é composta por 38 Institutos Federais de Educação, Ciência e Tecnologia (IFs) presentes em todos os estados, 2 Centros Federais de Educação Tecnológica (CEFETs), o Colégio Pedro II, a Universidade Tecnológica Federal do Paraná (UTFPR), além de 25 Escolas Técnicas vinculadas às Universidades Federais. Disponível em: http://redefederal.mec.gov.br/expansao-da-rede-federal.

3 Entendem-se aqui estudantes com transtornos de aprendizagem (dislexia, discalculia, disgrafia, disortografia) e com Transtorno de Déficit de Atenção e Hiperatividade (TDAH).

4 "Tecnologia assistiva ou ajuda técnica: produtos, equipamentos, dispositivos, recursos, metodologias, estratégias, práticas e serviços que objetivem promover a funcionalidade, relacionada à atividade e à participação da pessoa com deficiência ou com mobilidade reduzida, visando à sua autonomia, independência, qualidade de vida e inclusão social" (BRASIL, 2015, p.1).

${ }^{5}$ Nem todos os 36 Institutos Federais analisados disponibilizaram essa informação nos documentos institucionais. O recorte foi feito considerando as instituições que explicitaram esses dados.

${ }^{6}$ Informações da notícia publicada no site oficial do IFSP. Disponível em: https://www.ifsp.edu.br/ultimasnoticias/1588-diretoria-de-nucleos-fortalecera-acoes-afirmativas-e-educacao-inclusiva. Acesso em 12 de julho de 2020.

${ }^{7}$ As revistas podem ser acessadas pelo site https://ifsp.edu.br/acoes-e-programas/42-ensino/1472-acoesinclusivas.

${ }^{8}$ Os capítulos 21 e 22 do livro de Sonza et al (2020) trazem orientações e exemplos acerca do uso da tecnologia assistiva no contexto educacional. 
${ }^{9} \mathrm{O}$ modelo de Plano Educacional Individualizado (PEI) do IFRS encontra-se anexo à Instrução Normativa (IN) IFRS no 12/2018 (IFRS, 2018b), que se encontra disponível em: https://ifrs.edu.br/wpcontent/uploads/2018/12/IN-PEI-21.12_Publicada_em_271218.pdf.

\section{Correspondencia}

Andréa Poletto Sonza - Instituto Federal de Educação, Ciência e Tecnologia do Rio Grande do Sul, Reitoria, Rua General Osório, 348, Centro, Bento Gonçalves, Rio Grande do Sul - Brasil.

CEP: $95700-000$

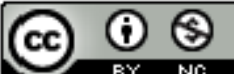

4.0 International (CC BY-NC 4.0) 